\title{
IDENTIFICATION OF OPERATING FLUIDS WITH FINGERPRINT METHOD UTILIZATION
}

\author{
Stefan Cornak \\ University of Defence in Brno, Czech Republic \\ stefan.cornak@unob.cz
}

\begin{abstract}
A lot of operating substances and materials are used for vehicle powertrain systems. For example, liquid fuels (diesel, petrol), lubrication oils (engine, transmission), lubrication greases, coolants and antifreeze additives, brake fluids, power transmission fluids, cleaning agents for parts of vehicles and many more. The identification of operating fluids is easy due to original packaging and its indication, if they are stored properly. However, operating fluids are very often stored in packaging, which is not marked. Therefore, sensory methods are applied: the operating fluids are distinguished from each other according to their appearance, colour, smell, flammability, foamability and others. Such subjective methods require very skilled assessment staff. In cases of contaminated or mixed operating fluids these sensory methods are usually insufficient. Therefore, this paper is concerned with a proposal of the fingerprint method for operating fluids with utilization of infrared spectrometry. The working principle of the method is measurement of infrared radiation absorbed by analysed substance with wavelengths from 600 to $1800 \mathrm{~cm}^{-1}$. The infrared spectrum is the analytical result of a specific substance. The final step is the comparison of a measured substance with the atlas or a kind of database of familiar operating fluids. Several spectra of operating fluids are mentioned in the last part of the paper. Results of the research have shown that the fingerprint method has proven its ability to clearly distinguish the kind of operating fluid from the others and determine the level of possible contamination with another operating fluid. In many cases it is possible to determine the quality indicators of measured operating fluids.
\end{abstract}

Keywords: operating fluids, infrared spectrometry, fingerprint method.

\section{Introduction}

A wide scale of operating substances and materials is used for vehicle powertrain systems. Among the essential ones are fluid and gas fuels, lubrication oils and lubrication substances, cooling fluids and anti-freezing liquids, brake liquids, power transmission fluids, cleaning agents for parts of vehicles and substances for cleaning and vehicles maintenance.

The basic condition for vehicle reliable operation is the addition of individual systems with the correct operating fluid in the required quantity and quality. The results of vehicle traffic monitoring at one state-owned company in the Czech Republic showed that $3 \%$ of the vehicles were diagnosed as defective on the grounds of the operating materials replacement [1]. In most cases there is unintentional confusion of fuels [2], oils, also brake fluids. However, it is necessary to consider also the deliberate mixing of other components, such as substances, which are taxed in another way in order to obtain illegal profits, or self-help fuel "improvement" by the consumer [3].

Life of the internal combustion engine is usually reduced in case of confusion of the engine oil to another engine oil. Replacing the gear oil for the motor oil causes seizing of the engine [4]. The diesel fuel mistaking with gasoline is very easy and causes permanent damage to injectors, a high pressure pump and engine mechanics. Considering the higher fuel gas flammability, in the extreme case, the vehicle may also start burning [2;5]. Mostly, however, the engine stops before the damage occurs. In case the brake fluid is exchanged, a car accident may occur as a result of the vehicle brake system failure [6].

The issue of operating materials identification is current in the army environment as well. Especially, during army activities abroad, in missions, when soldiers are supplied with local sources, it does not always have to be the declared operating fluid of the required quality. Therefore, it is necessary to pay essential attention to the identification of operating materials.

There are varieties of methods for identifying and evaluating operating materials. Generally, they can be divided into simple, standard and special.

Simple methods have their recognized place in the evaluation of operating fluids in operating practice, when it is necessary to identify operating liquid, or to determine its current state (satisfactory/unsatisfactory). Their essential limitation is dependent on their practical experience of an assessor/evaluator. As the result can be ambiguous, the aim is to find objective methods and 
procedures for evaluation and assessment. Operation fluid methods are oriented to assessment of colour, smell, clearness, foaming, corrosivity, etc.

Standard methods are complex and complicated laboratory methods, they are not suitable for the needs of practical use and the national state norm is their starting point document. The quality of fuels in the European Union or the Czech Republic is prescribed by this legislation ČSN EN 228 (Czech State Norm EN 228) motor fuels (unleaded petrol), ČSN EN 590 (Czech State Norm EN 590) motor fuels (diesel), ČSN EN 589 (Czech State Norm EN 589) motor fuels (liquefied petroleum gas) and ČSN 386110 (Czech State Norm 38 6110) Natural gas. In this standard the basic physico-chemical data of fuels are specified and the strict procedure of their evaluation before placing the fluids on the market and general requirements and methods of an assessment according to the European Union norm for fuels [7].

SAE J 1703 B, FMVSS CFR571.116f, ISO 4925, etc. represents the world-wide significant standard evaluation of glycol brake fluids. It is namely the determination of boiling point (dry and wet), kinematic viscosity, $\mathrm{pH}$ value, colour, compatibility with elastomers, oxidation and chemical stability, anticorrosive action, mix ability and storability [8;9].

The quality of cooling fluids is prescribed either by norms of the vehicle producers or by national norms (in the USA, France, England, etc.). It is namely determination of the water content, free alkalinity, density at $20{ }^{\circ} \mathrm{C}, \mathrm{pH}$ of hydrous solution (ratio 1:1) [10].

The above mentioned methods and procedures are classical laboratory methods. They are used by operating fluids manufacturers. However, the physico-chemical parameters of these standards are the basis for evaluation liquids in operation [11-16].

Special methods are very expensive; nevertheless, they enable us to evaluate more physicochemical properties of operation fluids all at once. It involves the use of advanced technologies using measuring instruments devices, calculating techniques and special software to make measurements and evaluate the measured results.

There is an equipment device at the Department of Specialization. These methods have increasingly greater use, especially in operational practice in assessing the degradation of operating fluids during transport operations of machines and devices. Their partial deficiency is that they are designed to evaluate selected parameters and for one liquid only.

It is apparent from the above that it would be useful, if there was one general procedure in operation evaluation of the basic operating fluids. This mentioned issue is presented in the article.

\section{Materials and methods}

Infrared spectrometry with use of Fourier transformation (FTIR) is one of the modern methods appropriate for operating fluids identification and following determination of the physico-chemical parameters. The principle of infrared spectrometry is based on Lamber-Beer law, which has an exponential form and can be mathematically expressed as follows:

$$
I=I_{0} \cdot e^{-\varepsilon . c . l}
$$

where $I_{0}$ - incident radiation intensity;

$I$ - passing radiation intensity;

$\varepsilon_{0}$ - molar absorb coefficient;

$l$ - absorb medium thickness;

$c$ - concentration of monitored substance.

The interferometer principle of a Michelson-type is clear from Figure 1. The ray from the infrared source 1 is directed through the mirror 2 to the semi-permeable mirror 3. One ray is reflected by the fixed mirror 4 and the other ray is reflected by the moveable mirror 5 . Both rays are put together again in the semi-permeable mirror 3 and then are routed towards the measuring cuvette 6 and from there through the mirror 7 to the infrared detector 8 . Spectrogram is the measurement result.

On the workplace operating fluids samples of various ages and quality were analyzed. For example, in the paper, ten samples of new basic operating fluids for vehicles were analyzed for comparison. 


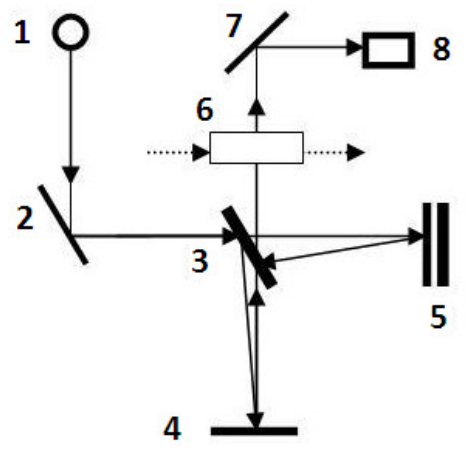

Fig. 1. Michelson-type interferometer principle diagram [17]

1 - infrared source; 2, 7 - mirror; 3 - ray divider (semi-permeable mirror); 4 - fixed mirror; 5 - moveable mirror; 6 - measuring cuvette; 8 - infrared detector

Analysis itself was performed on the Department of Combat and Special Vehicles by instrumental equipment IROX DIESEL, which works based on the principle of the Michelson's interferometer with Fourier transformation. Equipment calibration was performed by $99+\%$ n-hexan calibration liquid before the start of measuring. The measurement was repeated three times. MINIWIN 2.2.4 software was used for evaluation of the measuring results.

\section{Results and discussion}

Results of measuring of operating fluid samples are shown in Figures 2 to 11. It is a basic database of new operating fluids of vehicles. It is evident from the charts that each operating fluid has its typical spectrum.

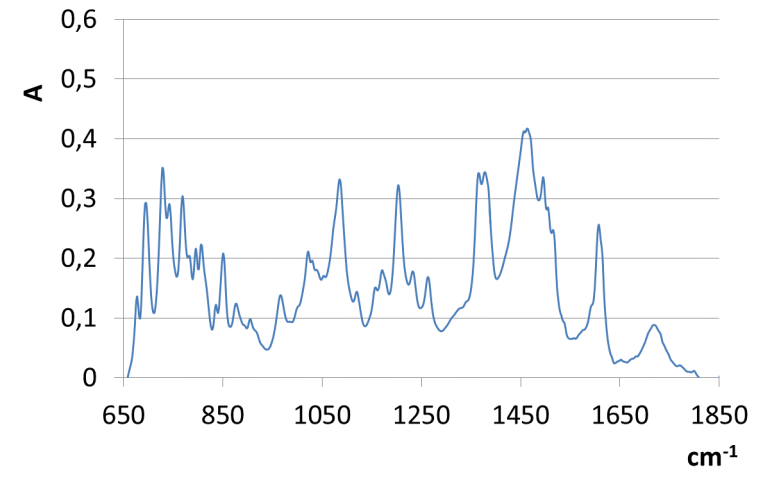

Fig. 2. Infrared spectrum (fingerprint) petrol (BA 95)

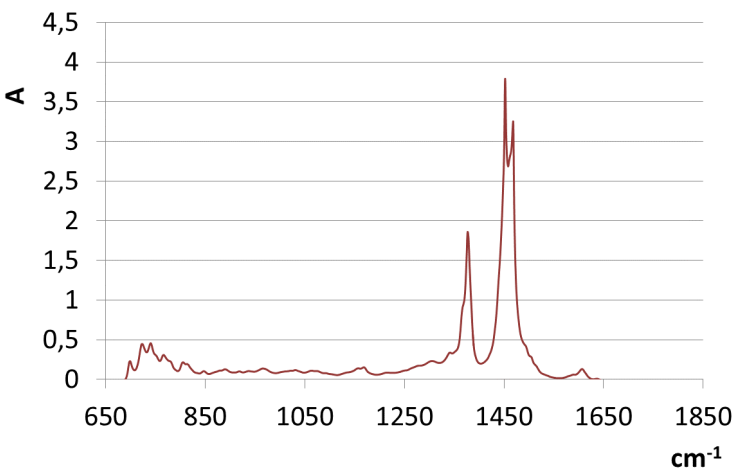

Fig. 4. Infrared spectrum (fingerprint) diesel fuel (F54)

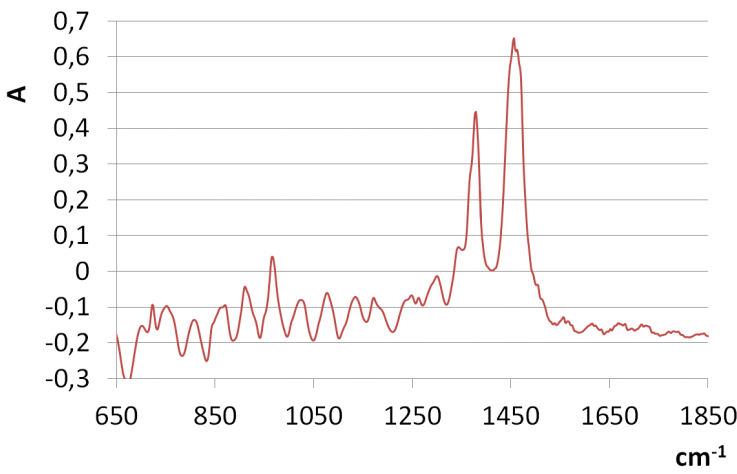

Fig. 3. Infrared spectrum (fingerprint) technical petrol

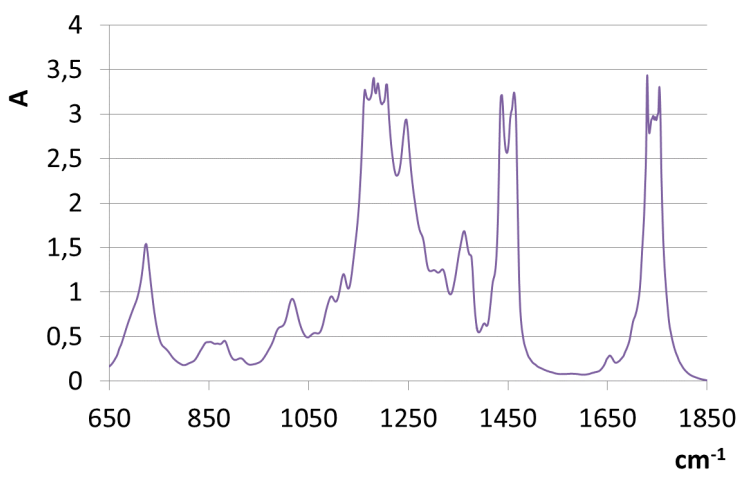

Fig. 5. Infrared spectrum (fingerprint) bio diesel (FAME) 


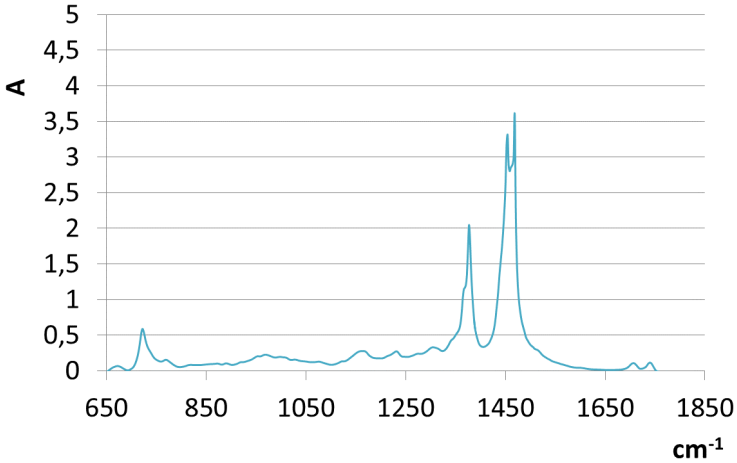

Fig. 6. Infrared spectrum (fingerprint) oil SAE 5W-30 MOBIL SUPER 3000

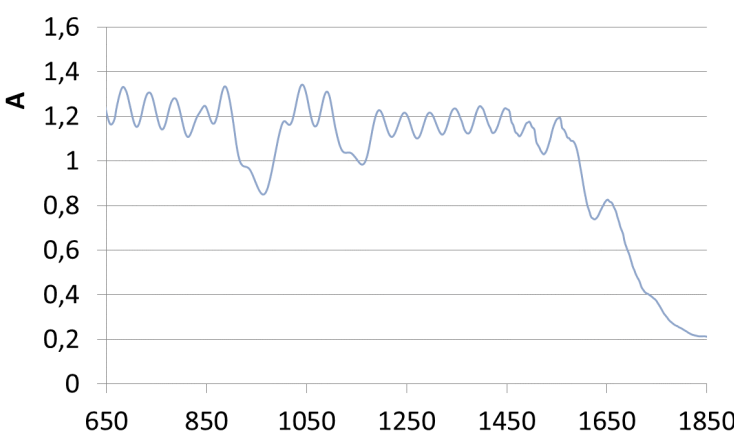

Fig. 8. Infrared spectrum (fingerprint) cooling fluid EVOX G30

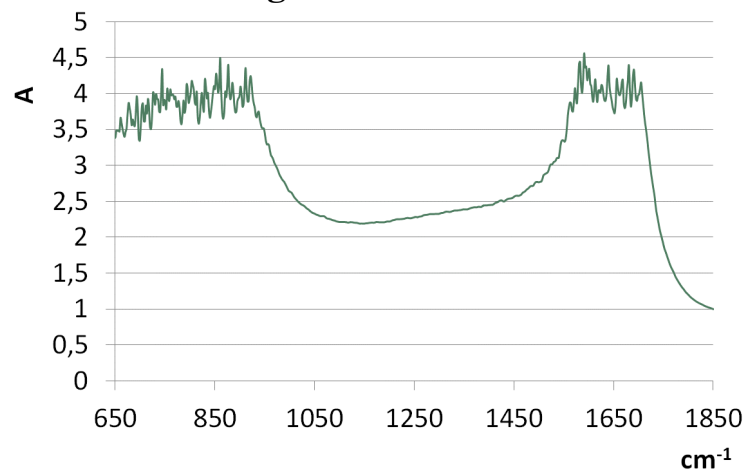

Fig. 10. Infrared spectrum (fingerprint) distilled water

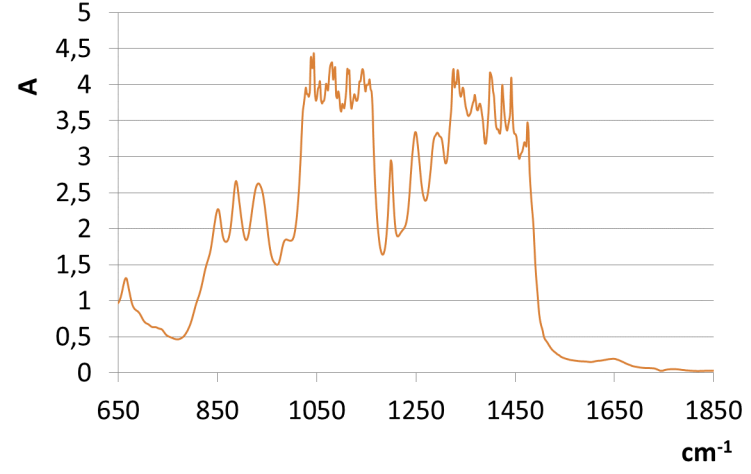

Fig. 7. Infrared spectrum (fingerprint) brake fluid DOT 4 HEKRA

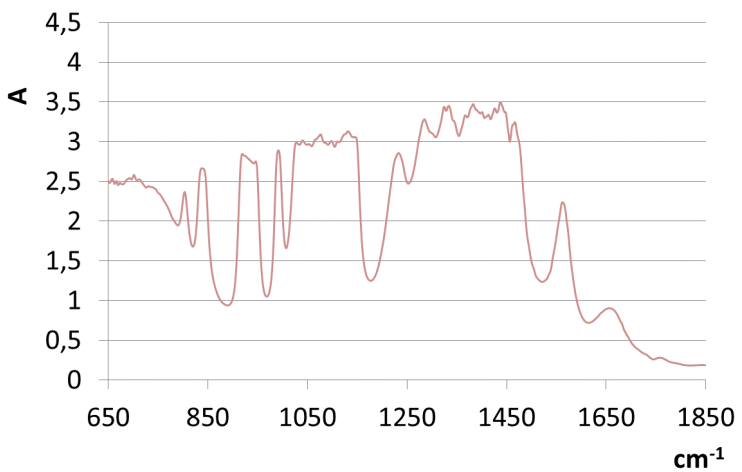

Fig. 9. Infrared spectrum (fingerprint) cooling fluid SHERON

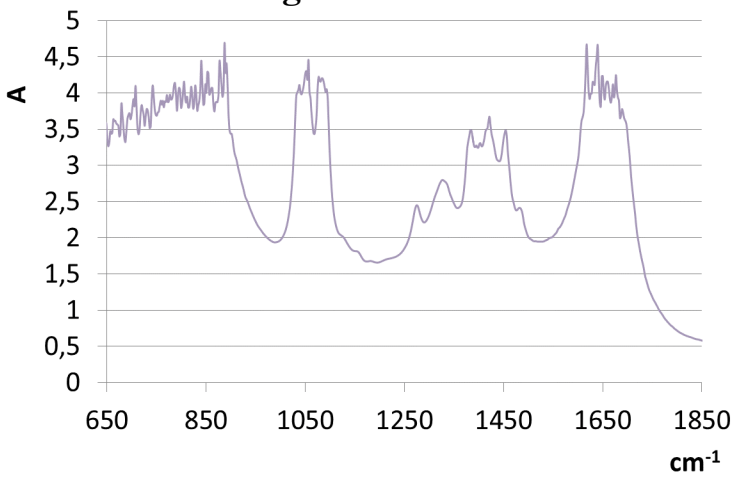

Fig. 11. Infrared spectrum (fingerprint) Windshield washer fluid (SHERON)

Spectrum in the range $600-1800 \mathrm{~cm}^{-1}$ is called "fingerprint area", where the peak position (wave number) corresponds to characteristic groups of individual operating fluids. Individual operating fluids can be identified unambiguously by the spectra. Peaks in the range $1370 \mathrm{~cm}^{-1}$ to $1460 \mathrm{~cm}^{-1}$ are typical of fuels and engine oils (Fig. 2, 3, 4, 5 and 6). So called "band peaks" are typical for other operating fluids, such as the brake fluid, (Fig. 7) with the center around the wave numbers between $1100 \mathrm{~cm}^{-1}$ and $1350 \mathrm{~cm}^{-1}$, distilled water (Fig. 10) with the center around the wave numbers between $800 \mathrm{~cm}^{-1}$ and $1660 \mathrm{~cm}^{-1}$ and windscreen washer fluids (Fig. 11) with the center around the wave numbers between $1100 \mathrm{~cm}^{-1}$ and $1420 \mathrm{~cm}^{-1}$.

For illustration, spectra of nine operating fluid samples are shown in Figure 12. It can be traced from the spectra that the sample is a diesel fluid (typical peaks around wavelets of $1370 \mathrm{~cm}^{-1}$ and $1460 \mathrm{~cm}^{-1}$ ). It is also obvious from the figure that the diesel fuel is of different ages (typical peaks around the wavelet of $1180 \mathrm{~cm}^{-1}$ ) and has various contents of FAME (typical peaks around the wavelet of $\left.1750 \mathrm{~cm}^{-1}\right)$. 


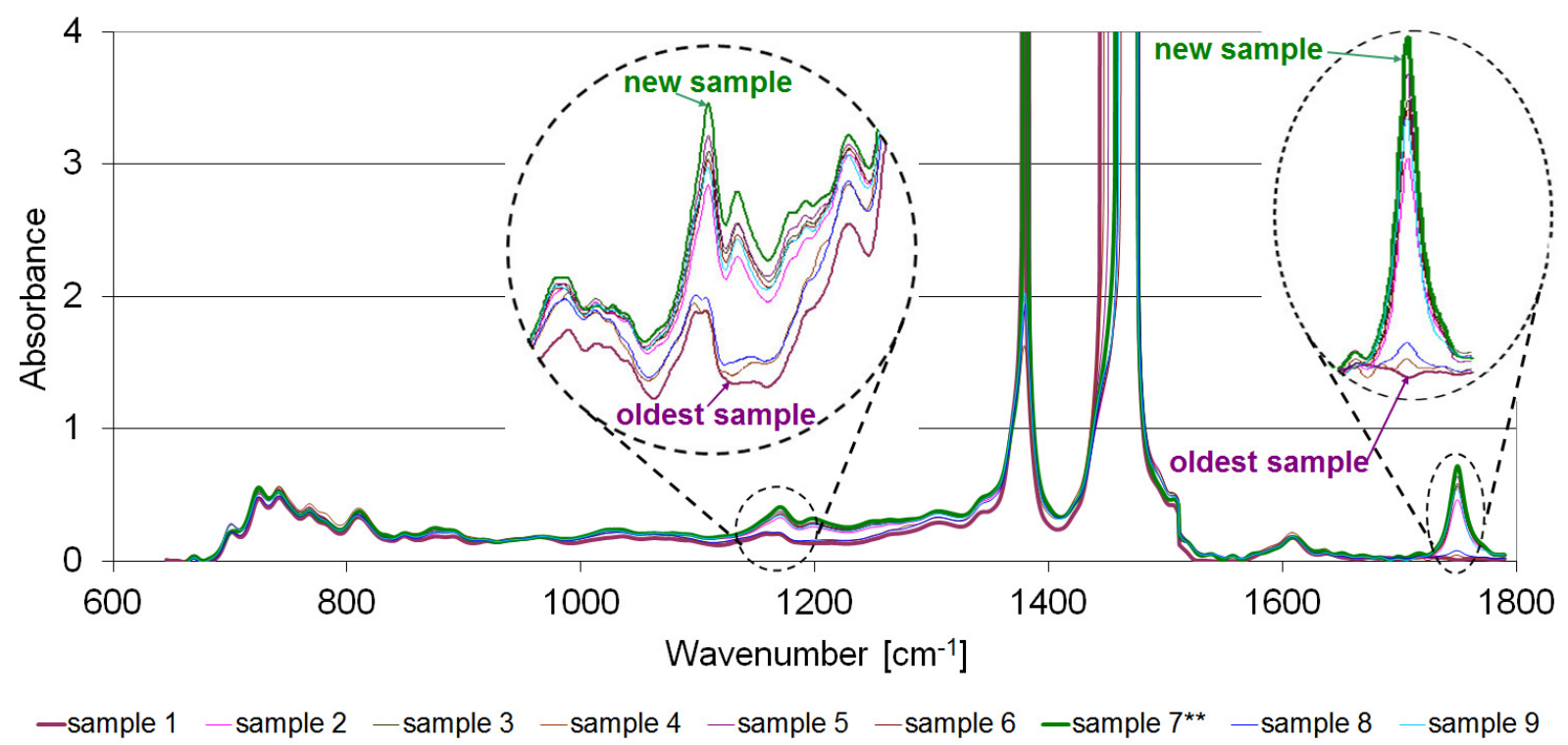

Fig. 12. Spectrum results of nine diesel fuel samples measured

Two sample spectrum of the same operating fluid is shown in Figure 13. It is evident from the spectrum that it is motor oil (typical peaks around the wavelets of $1376 \mathrm{~cm}^{-1}, 1452 \mathrm{~cm}^{-1}$ and $1470 \mathrm{~cm}^{-1}$ ). It is also clear that the motor oil is of different ages (typical peaks around the wavelets $740 \mathrm{~cm}^{-1}$ and $1200 \mathrm{~cm}^{-1}$ ) and contents the FAME from diesel fuel (typical peaks around the wavelet of $\left.1750 \mathrm{~cm}^{-1}\right)$.

Contamination of motor oil by FAME can occur in practical operation because of imperfect combustion of fuel and infiltration of diesel fuel to motor oil through piston rings. Other operating materials can be identified by a similar approach.

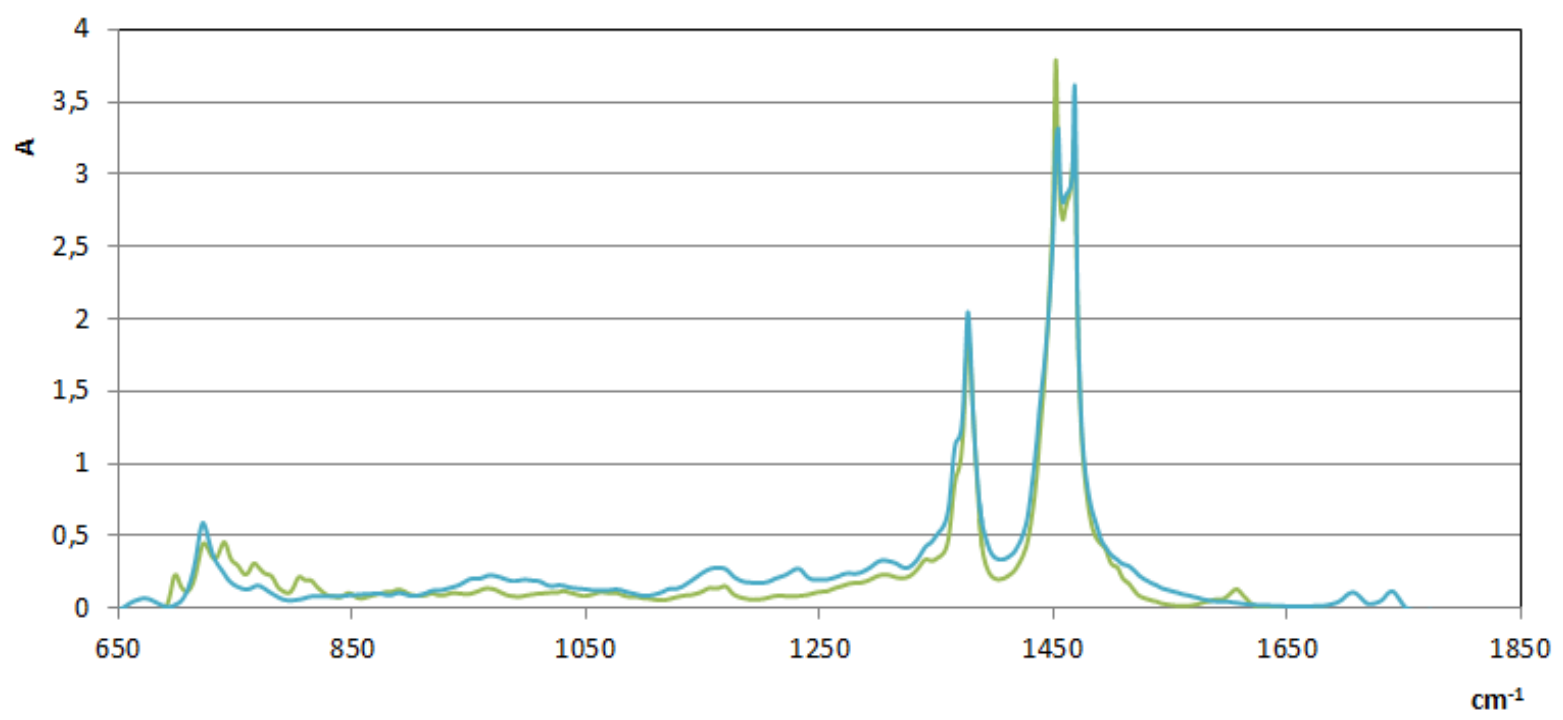

Fig. 13. Spectrum results of two oil fuel samples measured

It is necessary to state that the wide database of the basic operating fluids of different ages and different qualities has been available on the workplace of the researcher. The database is accessible to the expert public.

\section{Conclusions}

There has been created an extensive database of the basic operating fluid spectra. There can be found spectra not only of new fluids, but also service fluid spectra of different ages and different qualities. The research results have proved that the type of operating fluid can be identified simply with use of spectrum obtained from an infrared spectrometer by the Fingerprint method. The 
advantage of this method is mainly the analysis speed and a small amount of needed liquid samples. Quality indexes of the analysed operating fluids of vehicles can be determined by spectrum measured by infrared spectrometry with use of mathematical software.

\section{Acknowledgement}

The presented paper has been prepared with the support of the Ministry of Defence of the Czech Republic, Partial Project for Institutional Development, K-202, Department of Combat and Special Vehicles, University of Defence, Brno.

\section{References}

[1] Zajíček V. Optimization the quality management system for supplying of POL. Dissertation thesis. UO Brno 2014. (In Czech)

[2] Mužíková Z., Šimáček P., Hála S. Diesel fuel contamination by motor petrol. Collection of lectures 12. conference REOTRIB 2006, 17.-19. 5. 2006, pp. 158-164. (In Czech)

[3] Káňa J., Chudoba J., Šimáček P., Pospíšil M. Determination of Trace Concentrations of Biodiesel in Aviation Kerosin. Chemické listy, 2013, č. 106, p. 665-671. (In Czech)

[4] Stodola J., Chovanec A., Lipták P., Stodola P., Breznická A. Diagnosis Engine Oils utilizing Infrared Spectroscopy. In: 2017 International Conference on Military Technologies (ICMT). Piscataway, NJ 08854-4141 USA: Institute of Electrical and Electronics Engineers Inc., 2017, pp. 93-96.

[5] Třebický V. Fuels quality monitoring in Czech Republic. $8^{\text {th }}$ International Symposium 2008. Slovak Republic, Tatranské Matliare 2008. (In Czech)

[6] Čornák Š. Prediction of the brake fluids quality and the vehicle safety. In: Transport Means 2010. Kaunas: Kaunas University of Technology, 2010, pp. 116-119.

[7] Matějovský V. Vehicle fuels. Grada 2004, ISBN 80-247-0350-5. (In Czech)

[8] SAE J 300,SAE J 1703, SAE J 1704.

[9] Company standard for the determination of water content in brake fluids PP 45/41[In Czech]. Velvary, Velvana, a.s., 2005. 25 p.

[10] VW TL 774 - 10-2009, Wolfsburg: Volkswagen Aktiengesellschaft, 2009. $13 \mathrm{~s}$.

[11]Ben Amara A., Dauphin R., Babiker H., et al. Revisitingdiesel fuel formulation from Petroleum light and middle refinery streams based on optimized engine behavior, FUEL Vol: 174, 2016 pp. 63-75.

[12] Capone S., Zuppa M., Montagna G. et. al. October. Application of a gas sensors array to the detection of fuel as contamination defect in engine oil. In: Sensors, 2008 IEEE, pp. 442-445.

[13] Caneca A. R., Pimentel M. F., Galvao R. K. H. et. al. Assessment of infrared spectroscopy and multivariate techniques for monitoring the service condition of diesel-engine lubricating oils. Talanta, 70(2), 2006, pp. 344-352.

[14] Marinovič S., Jukič A., Doležal D. et al. Prediction of used lubricating oils properties by infrared spectroscopy using multivariate analysis. Goriva i maziva, 51(3), 2012, pp. 205-215.

[15] Severa L., Buchar L., Kumbar V., Čupera J. Engineering Flow Properties of Used and New Engine Oils. Nitra: Slovak University of Agriculture in Nitra, Applications of Physical Research in Engineering. 1. ISBN 978-80-552-0839-8. 2012, pp. 97-112.

[16] Kao M.-J., Tien D.-C., TingC.-C., Tsung T.-T.: Hydrophilic characterization of automotive brake fluid. Journal of Testing and Evaluation, 2006, Vol. 34, No. 5, pp. 400-404. ISSN 0090-3973.

[17] Irox diesel. Portable FTIR fuel analysis. Grabner instruments ${ }^{\text {TM }}$, Vienna 2006. 